\title{
Comments on New Integrative Photomedicine Equipment for Photobiomodulation and COVID-19
}

\author{
Gerhard Litscher ${ }^{1, *(1)}$ and Laura Marinela Ailioaie ${ }^{2}$ (D) \\ 1 Research Unit of Biomedical Engineering in Anesthesia and Intensive Care Medicine, Research Unit for \\ Complementary and Integrative Laser Medicine, and Traditional Chinese Medicine (TCM) Research Center \\ Graz, Medical University of Graz, Auenbruggerplatz 39, 8036 Graz, Austria \\ 2 Department of Medical Physics, Alexandru Ioan Cuza University, 11 Carol I Boulevard, 700506 Iasi, Romania; \\ lauraailioaie@yahoo.com \\ * Correspondence: gerhard.litscher@medunigraz.at; Tel.: +43-316-385-83907
}

\section{check for}

updates

Citation: Litscher, G.; Ailioaie, L.M. Comments on New Integrative Photomedicine Equipment for Photobiomodulation and COVID-19. Photonics 2021, 8, 303. https:// doi.org/10.3390/photonics 8080303

Received: 17 June 2021

Accepted: 27 July 2021

Published: 29 July 2021

Publisher's Note: MDPI stays neutral with regard to jurisdictional claims in published maps and institutional affiliations.

Copyright: (c) 2021 by the authors. Licensee MDPI, Basel, Switzerland. This article is an open access article distributed under the terms and conditions of the Creative Commons Attribution (CC BY) license (https:/ / creativecommons.org/licenses/by/ $4.0 /)$.

\begin{abstract}
Up to now it has not yet been scientifically proven whether the technical methods of photonics in the field of photobiomodulation (PBM), photodynamic therapy (PDT), and laser acupuncture in connection with COVID-19 have achieved effective medical success. As part of this short technical note, an overview of the current scientific status is given and new equipment from our own research area is briefly presented. Although there are still many unanswered questions, it seems to be emerging that PBM and PDT in connection with the corresponding photosensitizers may make it appear worthwhile to perform experimental and clinical studies, primarily as so-called home therapy studies. In any case, the technical requirements for this are already in progress.
\end{abstract}

Keywords: photobiomodulation (PBM); photodynamic therapy (PDT); laser acupuncture; photomedicine; COVID-19; SARS-CoV-2 virus

\section{Introduction}

The effects of light have been well-known in medicine for thousands of years. The father of the so-called "modern" Western medicine, Hippocrates, used heliotherapy to treat sick people in the Greek island of Kos. In addition, scientific treatment strategies with different light sources have existed in western medicine since about the middle of the last century [1,2]. In connection with traditional Chinese medicine (TCM) for example, the famous doctor Sun Simiao from the Chinese province of Shanxi has achieved great importance in describing the importance of the light therapy established in the Tang Dynasty for strengthening the so-called Qi [3].

The world's first laser was developed around 60 years ago. At that moment, nobody would have thought that the term "light amplification by stimulated emission of radiation" (LASER) would become synonymous with accuracy, precision, stimulation, and therapeutic option of the future, even in evidence-based traditional medicine. It was Albert Einstein who first described this stimulated emission in 1916 [4]. After Charles H. Townes had implemented the so-called MASER (microwave amplification through stimulated radiation emission), Theodore Maiman's first laser was in operation for the first time on 16 May 1960 [5].

The scientific literature on laser acupuncture for example is quite extensive, although the mechanisms and effects have not yet been proven down to the smallest detail. The PubMed scientific database (as of 8 June 2021) contains 1090 referenced publications on laser acupuncture. Recent studies comparing the effects of laser and needle acupuncture have contributed to a better understanding and it was shown that laser light can be used successfully, efficiently, and safely in acupuncture treatments.

The occurrence of the SARS-CoV-2 virus, and the respiratory disease known as COVID19 (Coronavirus Disease-19), is said to have started in China as early as September 2019 [6,7] 
and ultimately led to a pandemic in April 2020 [8]. "The coronavirus then began to spread between 13 September and 7 December-more and more people were infected," says Peter Forster, first author of one in Proc. Natl. Acad. Sci. USA (Impact Factor 9.58) published work $[6,7]$.

This short article is intended to provide a brief insight into the current situation and knowledge of laser acupuncture and laser/photo medicine in connection with COVID-19. A technical note on a topic such as COVID-19 can only be a snapshot, as there is hardly any other medical/technical field where the development of new findings and strategies is progressing faster than the subject matter.

\section{Definition of Laser Acupuncture}

The term laser acupuncture was first used in 1978 in the magazine "Omni" when a laser system was introduced by the German company Messerschmitt-Bölkow-Blohm (MBB) [2,9]. Until recently, however, there was no accepted definition of the term laser acupuncture. At the 12th World Association for PhotobiomoduLation Therapy (WALT) Congress in Nice in France all invited speakers and 28 experts from around the world agreed on the proposed definition of laser acupuncture, which is as follows [10]:

"Photonic stimulation of acupuncture points and areas to initiate therapeutic effects similar to those of needle acupuncture and related therapies along with the benefits of PhotoBioModulation (PBM)."

\section{COVID-19: TCM, Acupuncture and Photonics}

First of all, something important: using acupuncture/laser acupuncture COVID-19 cannot be cured. Nevertheless, it seems appropriate to discuss briefly in a scientific journal like Photonics (MDPI) about the possibilities of relieving symptoms, as already practiced in Wuhan in early 2020.

After coronavirus infections in China had increased a thousand times a day in February 2020, epidemiologists already estimated when the outbreak is likely to peak. Some speculated that it will take some months and that the virus is able to infect millions or hundreds of millions of people [11,12]. What some considered unlikely in February 2020 now seems to be confirmed. As of mid-June 2021, an estimated 172 million people worldwide are already infected with the virus and 3.7 million people died.

TCM and complementary medicine has also been used to alleviate and prevent epidemics for hundreds of years. The "National Health Committee" in China has published several editions of the "Diagnosis and Treatment Plan" for the novel "Coronavirus Pneumonia" (according to WHO: COVID-19). Treatment for COVID-19 with integrated Chinese and western medicine has been carried out across the country in China. There were also specialized scientific research institutions, hospitals, and companies that jointly conducted an online consultation of TCM experts for COVID-19 patients [12].

Treatment according to the "National Plan" initiates the clinical practice of TCM therapy as early as possible, reduces fever, improves cough, asthma, and gastrointestinal symptoms in a timely and effective manner and improves the healing rate. The combination of TCM and western medicine can effectively relieve symptoms in patients with mild COVID-19. In moderate and severe courses, integrative treatment can reduce lung exudation and inhibit the further development of the disease [8,12-14].

Acupuncture and moxibustion are important components of TCM. In the past, burning moxa leaves were used as moxibustion on acupuncture points to prevent epidemics. By stimulating acupuncture points, moxibustion has the function of warming yang, dispersing cold, activating meridians, strengthening yang., and removing toxins. Modern research on moxibustion has revealed its obvious effects on the regulation of immune function and the autonomic nervous system $[8,12]$.

For the further prevention, diagnosis, and medical treatment of COVID-19, the "China Association of Acupuncture-Moxibustion (CAAM)", as a group member of the World Association of Acupuncture-Moxibustion Societies (WFAS), has brought together experts 
in acupuncture and moxibustion. These experts in prevention and control of COVID-19 began to work as soon as the epidemic of the time became known. The group has published guidelines for acupuncture and moxibustion intervention in COVID-19.

Although some research has shown that moxa contains antiviral components, the influence of smoke is taken into account when used in the closed environment of the isolation ward, so acupressure application, pressing of seeds on ear acupuncture points, and massage, etc., continue in practice are common as manual needle acupuncture. The generally recommended acupuncture points for moxibustion and (laser) acupuncture point application are Zusanli (Ma 36), Guanyuan (KG 4) Dazhui (LG 14), Fengmen (BL 12), and Feishu (BL 13), other acupuncture points such as Zhongwan (KG 12) and Shenque (KG 8) are applied according to the symptoms. Acupuncture therapy can effectively improve symptoms such as loss of appetite, cough, insomnia, and headaches in COVID-19 patients $[8,12,15]$.

Although TCM can obviously be used very sensibly for COVID-19 [16], needle acupuncture has some limitations. In this particular medical situation, there is a rest risk of infection and restrictions in practical use not only during pandemic. However, there are already alternatives for needle acupuncture. Computer-controlled laser acupuncture based on photonic technology is one of the possibilities, and robot-controlled acupuncture using photonics methods is not far from clinical application these days $[12,17,18]$.

\section{COVID-19-Photonics: Effectiveness of Integrative Photomedicine?}

In Wuhan 16 hospitals were built in the first half of 2020, but only one named "Jiangxia" specializes primarily in TCM. More than 500 patients with mild symptoms of COVID19 were treated there with traditional herbs and other complementary methods such as acupuncture $[8,19,20]$.

During the COVID-19 in Wuhan, China sent over 3200 medical staff from its 600 TCM hospitals to Hubei Province. The State Administration for TCM also sent experts under the direction of three professors Zhang Boli, Huang Luqi, and Tong Xiaolin to the epidemic center [20].

The combination of TCM and western medicine was effective in relieving fever, dry cough, headache, sore throat, fatigue, diarrhea, and other symptoms in patients with mild COVID-19. In particular, the transition from mild-moderate to severely critical phases of COVID-19 occurred in $10 \%$ of patients who received western medicine only, compared to only $4.1 \%$ of patients who received both western and TCM therapy [20].

China wants to share its experience with other countries around the world during the COVID-19 pandemic. It will be interesting to see whether the global crisis will lead to complementary medicine standardization for such pandemics or whether TCM including acupuncture and laser acupuncture, as a valuable part of integrative (photo) medicine (Figure 1), will mainly be reserved for eastern countries [20,21].

In connection with COVID-19, the question arises: Can photomedicine and laser/ photoacupuncture be used for COVID-19? In the following sections, some areas of the current scientific literature on innovative photomedicine and COVID-19 are critically summarized and explained [22,23].

Integrative medicine, including TCM with acupuncture, has been shown to be effective in the rehabilitation of COVID-19 patients as previously described [8,15,19,24,25].

However, scientific laser societies dealing with the subject are currently finding it very difficult to recommend guidelines for the appropriate treatment or relief from laser therapy. A careful interpretation of articles published so far on COVID-19 and PBM or PDT [24,26-30], however, offers great potential for relatively new methods in the field of integrative photomedicine (see, for example, Figure 2). However, early conclusions must be avoided at all costs. 


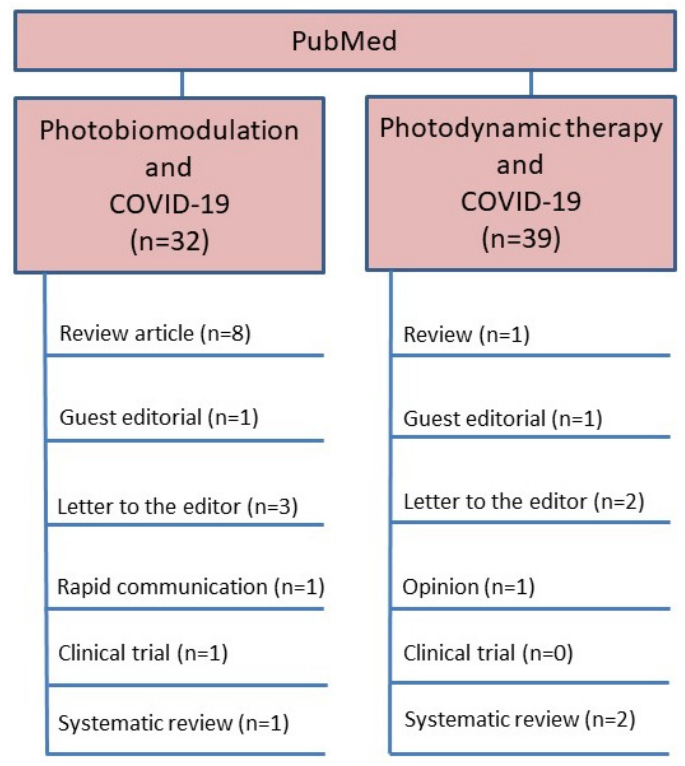

Figure 1. PubMed results on COVID-19 and photobiomodulation or photodynamic therapy (as of June 2021).

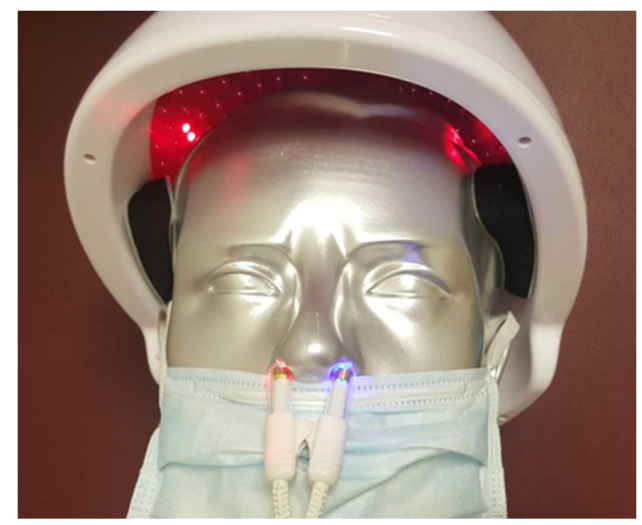

(a)

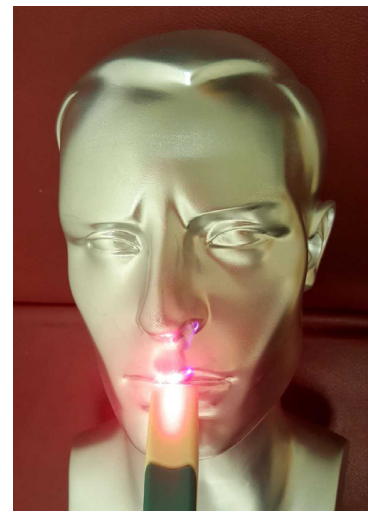

(b)

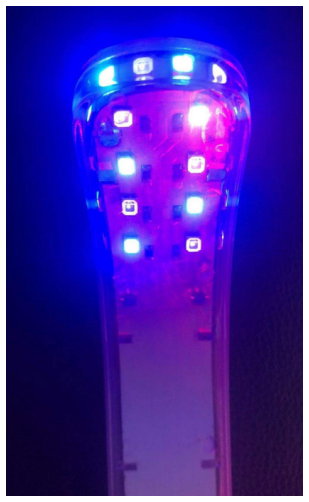

(c)

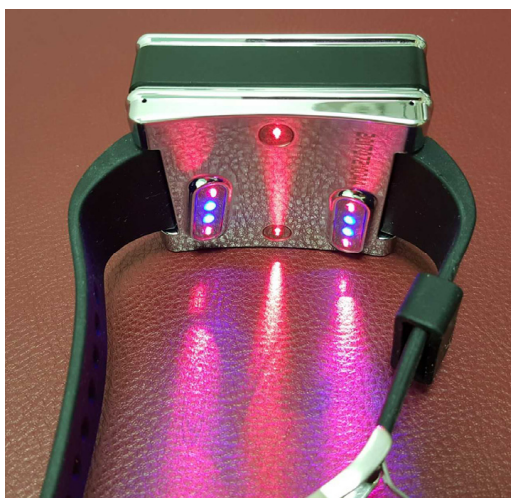

(d)

Figure 2. Examples of stimulation equipment for photobiomodulation and photodynamic therapy from the own research area of the TCM Research Center of the Medical University of Graz. In addition to the transcranial LED (light emitting diode) stimulation (a), a light stimulus application is possible via a nose adapter (a) (red, infrared, blue, or ultraviolet light irradiation) and a sublingual adapter (b). Local application using a so-called throat adapter (c) or systemic treatment using blood irradiation in the area of the radial and ulnar arteries using a so-called "laser watch" (d) [31] is also entirely conceivable. In addition to the blood irradiation, important acupuncture points in the area of the wrist groove can also be stimulated. 
The photomedicine helmet presented in Figure 2a is currently based on infrared LEDs using a wavelength of $810 \mathrm{~nm}$ [32]. The wavelength $810 \mathrm{~nm}$ has been proven recently to be one of the best for transcranial human stimulation [33]. The transcranial stimulation results were confirmed by measurements performed by our research team [5]; altogether 256 LEDs ( $60 \mathrm{~mW}$; one LED; $24 \mathrm{~mW} / \mathrm{cm}^{2}$; $\sim 15 \mathrm{~W}$ total helmet). The duration of the stimulation should be $15 \mathrm{~min}$ [32].

The nasal applicator, also shown in Figure 2a, has one red $(650 \mathrm{~nm})$ and one blue $(450 \mathrm{~nm})$ diode. The nasal mucous membrane is rich in capillaries and therefore suitable for intranasal blood irradiation. The laser output power is about $3 \mathrm{~mW}$. The time range is adjustable between 10 and $60 \mathrm{~min}$.

The sublingual applicator (Figure $2 \mathrm{~b}$ ) has three wavelengths $(635 \mathrm{~nm}, 536 \mathrm{~nm}$, and $405 \mathrm{~nm}$ ), $5 \mathrm{~mW}$ maximum output power each, in continuous mode, simultaneously, for 20 min daily. For hygiene reasons, a transparent foil is wrapped tightly around the tip of the probe. Its exact placement underneath the tongue is important, as the blood vessels are located there [34].

The throat applicator (see Figure 2c) has a curved end and thus makes it possible to irradiate deep into the throat (wavelength: $447 \mathrm{~nm}$ ) [35].

The laser watch (see Figure 2d) for systemic treatment and stimulation of, for example, the circulating riboflavin (photosensitizer) is attached to the wrist so that the light can penetrate the arteries.

All components are based on a non-invasive approach. Therefore, the system components can also be used as "home use system". Systemic stimulation of, for example, the circulating riboflavin takes place through the blue diodes $(447 \mathrm{~nm})$. Photodynamic therapy through the blood via wrist arteries could—at least that is speculated-also have a preventive effect [35].

Dominguez et al. [26] describe in a letter to the editor of the journal Photobiomodulation, Photomedicine and Laser Surgery entitled "Can transdermal photobiomodulation help us in the time of COVID-19?" various possibilities of non-invasive laser blood irradiation, which has already been used in numerous areas in Russia and Germany [36,37]. Unfortunately, the authors [26] cannot show any confirmed results in connection with COVID-19. Already on 24 April 2020 they documented, among other things: "We recommend the identification and treatment of hyperinflammation using a noninvasive therapy that exists with proven safety profiles to address the immediate need to reduce the rising mortality by performing projects that include transdermal PBM with application to $30 \mathrm{~min}$ per day for 3-5 days with diode laser whether visible or invisible." [26].

Fekrazad cites a good review of PBM and COVID-19 in a guest editorial in the same journal Photobiomodulation, Photomedicine and Laser Surgery on 23 April 2020 [27]. He describes the possibilities of PBM and antiviral PDT as an optional novel approach in COVID-19 management. He writes: "Of course, in the future, the use of a different modality of PBM and PDT can be evolved and, by using monoclonal antibodies we could target lung tissue specifically. It can even be improved by using Nano technology, making new photosensitizers in Nano scales, and pasting them to the target tissues to obtain better results." [27].

The scientific literature on laser/photomedicine around the world offers promising approaches for attempts to control bacterial and viral infections in humans, although no such evidence is yet available for COVID-19. For example, Kingsley et al. [38] in the US investigated the potential of visible monochromatic violet light $(405 \mathrm{~nm})$ as a nonthermal intervention for viruses in foods such as berries, which are susceptible to norovirus contamination. The authors showed that the use of singlet oxygen in food in combination with light in the visible spectrum could provide a means of inactivating foodborne viruses.

Another study from Iran examined the effects of riboflavin (RB) in combination with different doses of ultraviolet light (UV) on the platelet concentrate (PC) infected with three virus models [39]. The study showed that RB/UV treatment was shown to be a promising technique for reducing pathogens and had limited effects on platelet quality [39]. 
A study from Australia [40] showed that treatment with RB and UV light moderately lowers the dengue virus titers (DENV 1-4).

Authors from Sweden already stated in 2019 [41] that a high dose of blue light could possibly treat bacterial infections without losing human skin cells. They indicated that PDT using RB and blue light should be further investigated as it can be used in the treatment of skin conditions related to hyperproliferation of keratinocytes. As early as 2014, researchers from Beijing [42] developed a treatment device with RB and UV light to inactivate viruses in freshly frozen plasma (FFP) and showed an improved efficiency of virus inactivation, although the overall activity of the plasma factors was equally reduced.

Risk reduction strategies for transfusion-related acute lung injuries (TRALI) include the preferred use of male donors in the provision of FFP [43]. Authors from Spain pointed to the simplicity and feasibility that enables the implementation of RB and UV light-treated FFP [43].

In 2018, two authors from Great Britain [44] reported in a so-called "Perspective Article" that blue light undoubtedly has the potential to become a highly effective antimicrobial agent. However, the most important questions, including the mechanisms of toxicity and in particular the contribution of porphyrin-independent mechanisms, have yet to be answered [44].

In 2016, authors from Colorado [45] examined the effectiveness of RB and UV light against the Middle East respiratory syndrome coronavirus (MERS-CoV) tested in human plasma and reported that RB and UV light could reduce the increased risk of transfusion transmission of MERS-CoV.

The available scientific literature so far contains few publications on laser acupuncture in connection with COVID-19 that speak of the potential for it. Fekrazad mentioned in April 2020 [27] that laser acupuncture needs more attention. Liang and Litscher dealt in an editorial on 26 February 2020 [19] with the perspectives of robot-controlled (laser) acupuncture in connection with highly infectious diseases such as COVID-19 [18].

Does PDT now have potential in the treatment of COVID 19 patients? Moghissi et al. [46] from the Yorkshire Laser Center in Great Britain developed a new method in recent years that can be used for infections of the respiratory tract. The method is based on the use of an atomizer to dispense the photosensitizer. The drug is activated by light from 650-660 nm. In view of the lack of treatment options for COVID-19, the authors propose PDT already on 19 June 2020 as a possible therapeutic option [46].

In a letter to the editor of Photodiagnosis and Photodynamic Therapy, Dias et al. on 8 May 2020 [47] stated that there are many preclinical studies and photodynamic protocols for respiratory diseases and that there are certainly options for treatment strategies against infectious diseases such as COVID-19. However, they also write that they are working on the design of an "ideal" photodynamic protocol [47].

In a multidisciplinary perspective study by Weiss et al. [48] of 10 June 2020 that includes various areas such as virology, biology, medicine, engineering, chemistry, materials science, and computer science, the authors outline how strategies based on nanotechnology can fight against COVID-19 as well as can provide support against infectious diseases. Due to their properties nanoparticles could inactivate viruses, bacteria, fungi, or yeasts photothermally or by photocatalysis. In addition, the concept of "nanoimmunity by design" [48] could help design immune modulation materials that either stimulate or suppress the immune response, which could be used in the context of vaccine development for SARS-CoV-2. In addition to disease prevention and therapeutic potential, nanotechnology plays an important role in diagnostics and can support the development of simpler, faster, and more cost-effective methods to monitor the presence of SARS-CoV-2. Nanotechnology, according to the authors, is of vital importance in countering COVID-19 and will be just as important in preparing for future pandemics [48].

Almeida et al. [49] reported on 11 June 2020 that antimicrobial photodynamic therapy (aPDT) using known, safe, and inexpensive photosensitizers could help combat COVID19. This would be possible in different ways: either to prevent infections or to develop 
photoactive substances (e.g., masks, protective suits, gloves, etc.,) to disinfect surfaces, air, and waste water under artificial light and/or natural sunlight [49].

The development of therapeutic methods will continue to play an important role in the future with COVID-19, especially since the consistent containment of SARS-CoV-2 currently seems to be an important strategy from an epidemiological point of view.

PBM and PDT are very interesting and promising approaches to treating various diseases. However, the literature currently (June 2021) still lacks valid research results on PBM and related methods such as laser acupuncture and COVID-19 [50-55].

Exemplarily an article reports the case of a patient with oral manifestation of COVID19 treated with PBM and PDT [50]. A review article on multiple interactions between PBM, probiotics, and the human microbiota, their effects on the human body, and their implications for the management of viral infectious diseases has also been published [14]. Other authors present a small-scale clinical trial with ten patients randomized to standard medical care or standard medical care plus adjunctive photobiomodulation therapy (PBMT). The PBMT group received four daily sessions of near-infrared light treatment targeting the lung tissue via laser [51]. It was also shown that blue light is able to decrease the viral load. In a study, PBMT at blue wavelengths $(450,454$, and $470 \mathrm{~nm})$ was tested in an in vitro model of SARS-CoV-2 infection [52]. It might improve the efficacy of PBMT and PDT by using monoclonal antibodies and preparing new photosensitizers at nanoscale that target the lung tissue specifically. More animal and human studies are required to reach an effective protocol [53]. Another article has presented supportive PBMT in a patient with severe COVID-19 pneumonia. Respiratory indices, radiological findings, oxygen requirements, and patient outcomes improved over several days and without need for a ventilator. Further controlled clinical trials are required to evaluate the effects of PBMT on clinical outcomes in patients with COVID-19 pneumonia [54]. Weber et al. [35] for example investigated whether PDT with riboflavin (vitamin B2) and a specially designed laser/LED treatment kit can be used to treat patients with COVID-19 at early disease stages [35]. All 20 patients in the experiment group showed significant improvement in clinical symptoms and viral load assessment within the 5 days of PDT treatment. His group reported that the applied treatment is easy to perform at home and it is cost effective [35].

Litscher reported recently about three current study designs concerning PDT and COVID-19 for home monitoring. However, the study projects do not meet all the requirements of good scientific practice. Although the designs can be expected to provide scientifically assessable results, no scientific conclusion can currently (yet) be drawn that the three methods for the treatment of COVID-19 prove to be suitable [55].

This short technical note conflates three different aspects of photomedicine, namely laser acupuncture, photobiomodulation, and photodynamic therapy. These three methods have in common that they all use visible or invisible light. Laser acupuncture by definition uses lasers, but PDT and especially PBM now predominantly use LEDs instead.

PDT produces cytotoxic reactive oxygen species which can destroy microbial cells to treat some localized infections, but is at the moment not generally used to treat viral infections. In some cases, PDT can kill virally infected cells, and maybe this can be useful for COVID-19. It also has to be mentioned that moreover riboflavin is not really a strong photosensitizer. Nevertheless, PBM can affect the host tissue to reduce inflammation so it may be useful for COVID-19 in some cases. Laser acupuncture has a lot of medical applications, but currently is unlikely to attract sufficient medical attention in case of COVID-19.

\section{Conclusions}

This article aims to present a new equipment and a review with integrative photomedicine for PBM and COVID-19. Nowadays it is important to describe treatment/ therapies with randomized clinical trials that support the evidence. However, there are not any relevant clinical scientifically high level RCTs available yet on this special topic. 
From the authors' point of view of this short article, however, comprehensive clinical studies are a prerequisite for successful medical treatments. Nevertheless, we believe the readers of Photonics have a right to find out about this and also to briefly know what new developments on the subject are currently underway.

Author Contributions: Conceptualization, G.L. and L.M.A.; writing-original draft preparation, G.L.; writing-review and editing, G.L. and L.M.A. All authors have read and agreed to the published version of the manuscript.

Funding: This research received no external funding.

Institutional Review Board Statement: Not applicable.

Informed Consent Statement: Not applicable.

Data Availability Statement: Data supporting reported results can be found by the first author G.L.

Acknowledgments: The article was written using information sources from Fengxia Liang, director of the Acupuncture and Moxibustion Institute of Hubei University of Chinese Medicine in Wuhan, China. In 2017, Liang was visiting the first author G.L. at the Medical University of Graz in Austria, who is also visiting and honorary professor at the Hubei University for Chinese Medicine in Wuhan and at the Hubei Provincial Collaborative Innovation Center for preventive treatment through acupuncture and moxibustion in Wuhan, China.

Conflicts of Interest: The authors declare no conflict of interest.

\section{References}

1. Körbler, J. On the History of the Development of Sunlight Treatment. Hippokrates 1967, 38, 145-150. (In German) [PubMed]

2. Litscher, G. History of Laser Acupuncture: A Narrative Review of Scientific Literature. Med. Acupunct. 2020, 32, 201-208. [CrossRef]

3. Song, Z.M. Historical Origin of Jiu Tangshu Biography of Sun Simiao. Zhonghua Yi Shi Za Zhi 2012, 42, 264-271. (In Chinese) [PubMed]

4. Einstein, A. On the Quatum Theory of Radiation. Mitt. Phys. Ges. Zürich 1916, 18, 47-62. (In German)

5. Bahr, F.R.; Litscher, G. Laser Acupuncture and Innovative Laser Medicine; Bahr\&Fuechtenbusch Publisher: Munich, Germany, 2018; pp. 1-185.

6. Forster, P.; Forster, L.; Renfrew, C.; Forster, M. Phylogenetic Network Analysis of SARS-CoV-2 Genomes. Proc. Natl. Acad. Sci. USA 2020, 117, 9241-9243. [CrossRef] [PubMed]

7. Coronavirus: First Case on September 13th? Available online: https://www.nau.ch/amp/news/ausland/coronavirus-mehr-als150000-todesopfer-weltweit-65694944 (accessed on 2 June 2020). (In German)

8. Litscher, G. Effectiveness of Integrated Medicine in COVID-19? Editorial. Med. Acupunct. 2020, 32, 131-132. [CrossRef] [PubMed]

9. Bell, T.E. Laser acupuncture. Continuum Omni. 1978, 1, 43-47.

10. Litscher, G. Definition of Laser Acupuncture and All Kinds of Photo Acupuncture. Medicines 2018, 5, 117. [CrossRef]

11. Cyranoski, D. When Will the Coronavirus Outbreak Peak? Nature News. Available online: https:// doi.org/10.1038/d41586-020 -00361-5 (accessed on 18 February 2020).

12. Litscher, G.; Liang, F.X. COVID-19 (Coronavirus Disease-19): Traditional Chinese Medicine Including Acupuncture for Relief-A Report from Wuhan, Hubei Province, China. Akupunkt. Aurikulomedizin 2020, 46, 9-10. (In German)

13. Valussi, M.; Antonelli, M.; Donelli, D.; Firenzuoli, F. Appropriate Use of Essential Oils and Their Components in the Management of Upper Respiratory Tract Symptoms in Patients with COVID-19. J. Herb. Med. 2021, 28, 100451. [CrossRef]

14. Ailioaie, L.M.; Litscher, G. Probiotics, Photobiomodulation, and Disease Management: Controversies and Challenges. Int. J. Mol. Sci. 2021, 22, 4942. [CrossRef]

15. Lu, P.; Wang, S.; Tang, Z. Feasibility Analysis of Early Intervention of Moxibustion in the Prevention and Treatment of Novel Coronavirus Pneumonia. Acta Chin. Med. 2020, 19, 1-12.

16. Luo, Y.; Wang, C.Z.; Hesse-Fong, J.; Lin, J.G.; Yuan, C.S. Application of Chinese Medicine in Acute and Critical Medical Conditions. Am. J. Chin. Med. 2019, 47, 1223-1235. [CrossRef] [PubMed]

17. Litscher, G.; Litscher, D. Scientific Aspects of Innovative Laser Medicine. In Laser Acupuncture and Innovative Laser Medicine, 1st ed.; Bahr, F., Litscher, G., Eds.; Bahr \& Fuechtenbusch Publisher: Munich, Germany, 2018; Volume 1, pp. 13-77.

18. Lan, K.C.; Litscher, G. Robot-Controlled Acupuncture-An Innovative Step towards Modernization of the Ancient Traditional Medical Treatment Method. Medicines 2019, 6, 87. [CrossRef] [PubMed]

19. Liang, F.X.; Litscher, G. COVID-19 (Coronavirus Disease-19): Traditional Chinese Medicine Including Acupuncture for Alleviation-A Report from Wuhan, Hubei Province in China. OBM Integr. Complement. Med. 2020, 5, 4. [CrossRef]

20. Litscher, G. COVID-19: Effectiveness of Integrative Medicine? Akupunkt. Aurikulomedizin 2020, 46, 9. (In German) [CrossRef] 
21. Fleckenstein, J.; Füzeki, E.; Banzer, W. The Application of Traditional Chinese Medicine (TCM)/ Acupuncture in the Therapy and Prevention of SARS-CoV-2 Infections. Dtsch. Z. für Akupunkt. 2020, 63, 70-73. (In German) [CrossRef]

22. Litscher, G.; Weber, M. Research, Light, and COVID-19. Editorial. Akupunkt. Aurikulomedizin 2020, 46, 8. (In German)

23. Litscher, G. Can Laser Medicine and Laser Acupuncture Be Used for COVID-19? Selected Areas of the Current Scientific Literature. Editorial. OBM Integr. Complement. Med. 2020, 5, 6. [CrossRef]

24. Enwemeka, C.S.; Bumah, V.V.; Masson-Meyers, D.S. Light as a Potential Treatment for Pandemic Coronavirus Infections: A Perspective. J. Photochem. Photobiol. B Biol. 2020, 207, 111891. [CrossRef] [PubMed]

25. Li, M.; Yang, X.; Li, K.; Xie, Y.Q. Traditional Chinese Medicine for Novel Coronavirus Pneumonia Treatment: Main Force or Supplement? Tradit. Med. Res. 2020, 5, 62-64. [CrossRef]

26. Domínguez, A.; Velásquez, S.A.; David, M.A. Can Transdermal Photobiomodulation Help Us at the Time of COVID-19? Photobiomodul. Photomed. Laser Surg. 2020, 38, 258-259. [CrossRef]

27. Fekrazad, R. Photobiomodulation and Antiviral Photodynamic Therapy as a Possible Novel Approach in COVID-19 Management. Photobiomodul. Photomed. Laser Surg. 2020, 38, 255-257. [CrossRef] [PubMed]

28. Fernandes, A.B.; Lima, C.J.; Villaverde, A.G.J.B.; Pereira, P.C.; Carvalho, H.C.; Zângaro, R.A. Photobiomodulation: Shining Light on COVID-19. Photobiomodul. Photomed. Laser Surg. 2020, 38, 395-397. [CrossRef]

29. Camacho, A.D. Author's Response to Ferreira: Can Transdermal Photobiomodulation Help Us at the Time of COVID-19? An Update. Photobiomodul. Photomed. Laser Surg. 2020, 38, 328-331. [CrossRef] [PubMed]

30. Ferreira, M.V.L. Response to: Can Transdermal Photobiomodulation Help Us at the Time of COVID-19? Photobiomodul. Photomed. Laser Surg. 2020, 38, 326-327. [CrossRef] [PubMed]

31. Litscher, G.; Litscher, D. A Laser Watch for Simultaneous Laser Blood Irradiation and Laser Acupuncture at the Wrist. Integr. Med. Int. 2016, 3, 75-81. [CrossRef]

32. Litscher, G. Transcranial Laser Stimulation Research-A New Helmet and First Data from Near Infrared Spectroscopy. Medicines 2018, 5, 97. [CrossRef]

33. Wang, P.; Li, T. Which Wavelength is Optimal for Transcranial Low-Level Laser Stimulation? J. Biophotonics 2019, 12 , e201800173. [CrossRef]

34. Ailioaie, L.M.; Litscher, G.; Weber, M.; Ailioaie, C.; Litscher, D.; Chiran, D.A. Innovations and Challenges by Applying Sublingual Laser Blood Irradiation in Juvenile Idiopathic Arthritis. Int. J. Photoenergy 2014, 2014, 1-8. [CrossRef]

35. Weber, H.M.; Mehran, Y.Z.; Orthaber, A.; Saadat, H.H.; Weber, R.; Wojcik, M. Successful Reduction of SARS-CoV-2 Viral Load by Photodynamic Therapy (PDT) Verified by QPCR_A Novel Approach in Treating Patients in Early Infection Stages. Med. Clin. Res. 2020, 5, 311-325.

36. Weber, M. Photodynamic Low-Level-Laser-Therapy (PDT)-New Options in Oncology. In Laser Acupuncture and Innovative Laser Medicine, 1st ed.; Bahr, F., Litscher, G., Eds.; Bahr \& Fuechtenbusch Publisher: Munich, Germany, 2018; Volume 1, pp. 147-151.

37. Litscher, G.; Gao, X.Y.; Wang, L.; Zhu, B. High-Tech Acupuncture and Integrative Laser Medicine. Evidence-Based Complement. Altern. Med. 2012, 2012, 363467. [CrossRef]

38. Kingsley, D.H.; Perez-Perez, R.E.; Boyd, G.; Sites, J.; Niemira, B.A. Evaluation of 405-nm Monochromatic Light for Inactivation of Tulane Virus on Blueberry Surfaces. J. Appl. Microbiol. 2018, 124, 1017-1022. [CrossRef] [PubMed]

39. Mirshafiee, H.; Sharifi, Z.; Hosseini, S.M.; Yari, F.; Nikbakht, H.; Latifi, H. The Effects of Ultraviolet Light and Riboflavin on Inactivation of Viruses and the Quality of Platelet Concentrates at Laboratory Scale. Avicenna J. Med. Biotechnol. 2015, 7, 57-63. [PubMed]

40. Faddy, H.M.; Fryk, J.J.; Watterson, D.; Young, P.R.; Modhiran, N.; Muller, D.A.; Keil, S.D.; Goodrich, R.; Marks, D. Riboflavin and Ultraviolet Light: Impact on Dengue Virus Infectivity. Vox Sang 2016, 111, 235-241. [CrossRef]

41. Makdoumi, K.; Hedin, M.; Bäckman, A. Different Photodynamic Effects of Blue Light with and without Riboflavin on MethicillinResistant Staphylococcus Aureus (MRSA) and Human Keratinocytes In Vitro. Lasers Med. Sci. 2019, 34, 1799-1805. [CrossRef]

42. Zhu, L.; Pan, J.; Wie, C.; Wang, H.; Xiang, R.; Zhang, J.; Wang, D. The Effectiveness of Riboflavin Photochemical-Mediated Virus Inactivation and Changes in Protein Retention in Fresh-Frozen Plasma Treated Using a Flow-Based Treatment Device. Transfusion 2015, 55, 100-107. [CrossRef]

43. Jimenez-Marco, T.; Ruiz-Alderton, D.; Bautista-Gili, A.M.; Girona-Llobera, E. Role of Riboflavin- and UV Light-Treated Plasma in Prevention of Transfusion-Related Acute Lung Injury. Transfus. Med. Hemother. 2014, 41, 172-175. [CrossRef] [PubMed]

44. Gwynne, P.J.; Gallagher, M.P. Light as a Broad-Spectrum Antimicrobial. Perspective Article. Front. Microbiol. 2018, 9, 119. [CrossRef]

45. Keil, S.D.; Bowen, R.; Marschner, S. Inactivation of Middle East Respiratory Syndrome Coronavirus (MERS-CoV) in Plasma Products Using a Riboflavin-Based and Ultraviolet Light-Based Photochemical Treatment. Transfusion 2016, 56, $2948-2952$. [CrossRef]

46. Moghissi, K.; Dixon, K.; Gibbins, S. Does PDT have Potential in the Treatment of COVID 19 Patients? Photodiagn. Photodyn. Ther. 2020, 31, 101889. [CrossRef] [PubMed]

47. Dias, L.D.; Blanco, K.C.; Bagnato, V.S. COVID-19: Beyond the Virus. The Use of Photodynamic Therapy for the Treatment of Infections in the Respiratory Tract. Photodiagn. Photodyn. Ther. 2020, 31, 101804. [CrossRef] [PubMed]

48. Weiss, C.; Carriere, M.; Fusco, L.; Capua, I.; Regla-Nava, J.A.; Pasquali, M.; Scott, J.A.; Vitale, F.; Unal, M.A.; Mattevi, C.; et al. Toward Nanotechnology-Enabled Approaches against the COVID-19 Pandemic. ACS Nano 2020, 14, 6383-6406. [CrossRef] 
49. Almeida, A.; Faustino, M.A.F. Neves MGPMS. Antimicrobial Photodynamic Therapy in the Control of COVID-19. Antibiotics 2020, 9, 320. [CrossRef]

50. Garcez, A.S.; Delgado, M.; Sperandio, M.; Dantas E Silva, F.T.; Rita de Assis, J.S.; Suzuki, S.S. Photodynamic Therapy and Photobiomodulation on Oral Lesion in Patient with Coronavirus Disease 2019: A Case Report. Photobiomodul. Photomed. Laser Surg. 2021, 39, 386-389. [CrossRef] [PubMed]

51. Vetrici, M.A.; Mokmeli, S.; Bohm, A.R.; Monici, M.; Sigman, S.A. Evaluation of Adjunctive Photobiomodulation (PBMT) for COVID-19 Pneumonia Via Clinical Status and Pulmonary Severity Indices in a Preliminary Trial. J. Inflamm. Res. 2021, 14, 965-979. [CrossRef]

52. Zupin, L.; Gratton, R.; Fontana, F.; Clemente, L.; Pascolo, L.; Ruscio, M.; Crovella, S. Blue Photobiomodulation LED Therapy Impacts SARS-CoV-2 by Limiting Its Replication in Vero Cells. J. Biophotonics 2021, 14, e202000496. [CrossRef]

53. Fekrazad, R.; Asefi, S.; Pourhajibagher, M.; Vahdatinia, F.; Fekrazad, S.; Bahador, A.; Abrahamse, H.; Hamblin, M.R. Photobiomodulation and Antiviral Photodynamic Therapy in COVID-19 Management. Adv. Exp. Med. Biol. 2021, 1318, 517-547. [CrossRef] [PubMed]

54. Sigman, S.A.; Mokmeli, S.; Monici, M.; Vetrici, M.A. A 57-Year-Old African American Man with Severe COVID-19 Pneumonia Who Responded to Supportive Photobiomodulation Therapy (PBMT): First Use of PBMT in COVID-19. Am. J. Case Rep. 2020, 21, e926779. [CrossRef]

55. Litscher, G. Photobiomodulation and COVID-19: Selection of Study Designs for Possible Home Treatment-Critical Considerations. Akupunkt. Aurikulomedizin 2021, 47, 22-28. (In German) [CrossRef] 